\title{
Amphetamine Exposure Selectively Enhances Hippocampus-Dependent Spatial Learning and Attenuates Amygdala-Dependent Cue Learning
}

\author{
Rutsuko Ito*,' and Melissa Canseliet' \\ 'Department of Experimental Psychology, University of Oxford, Oxford, UK
}

\begin{abstract}
Behaviorally sensitizing regimen of amphetamine (AMPH) exposure has diverse effects on learning, memory, and cognition that are likely to be a consequence of long-term neural adaptations occurring in the cortico-limbic-striatal circuitry. In particular, altered dopamine signaling in the nucleus accumbens and medial prefrontal cortex has been implicated to underlie AMPH-induced changes in behavior. This study sought to test the hypothesis that repeated AMPH exposure disrupts the regulation of limbic information processing and the balance of competing limbic control over appetitive behavior. Mice received seven intraperitoneal injections of D-AMPH ( $2.5 \mathrm{mg} / \mathrm{kg}$ or $5 \mathrm{mg} / \mathrm{kg}$ ) or vehicle solution (saline) and were trained in ( 1 ) a simultaneous conditioned cue and place preference task using a six-arm radial maze, found to depend on the integrity of the hippocampus (HPC) and basolateral amygdala (BLA), respectively and (2) a conditional BLA-dependent cue, and HPC-dependent place learning task using an elevated T-maze. In both tasks, the vehicle pretreatment group initially acquired cue learning, followed by the emergence of significant place/spatial learning. In contrast, pretreatment with repeated $\mathrm{AMPH}$ caused marked deviations from normal acquisition patterns of place and cue conditioning, significantly facilitating HPC-dependent place conditioning in the first task while attenuating BLA-dependent cue conditioning in both tasks. These findings provide the first demonstration of an aberrant regulation of HPC- and BLA-dependent learning as a result of AMPH exposure, highlighting the importance of the meso-coticolimbic dopamine system in maintaining the balance of limbic control over appetitive behavior.

Neuropsychopharmacology (2010) 35, 1440-|452; doi:I0.1038/npp.20 I0.14; published online 3 March 2010
\end{abstract}

Keywords: conditioned place preference; learning and memory systems; nucleus accumbens; dopamine; schizophrenia; addiction

\section{INTRODUCTION}

Repeated exposure to amphetamine (AMPH) induces enduring behavioral and neural sensitization, which is revealed by the exaggeration of behavioral and neurochemical responses to subsequent acute AMPH challenge. It is used widely as an animal model of escalating drug craving in human addiction (Robinson and Becker, 1986; Robinson and Berridge, 1993, 2001), and much research has implicated long-term neural adaptations involving augmented dopaminergic neurotransmission in the striatum (Paulson and Robinson, 1995; Pierce and Kalivas, 1995, 1997) in underlying the expression of AMPH sensitization (see Vanderschuren and Kalivas, 2000 for review).

However, AMPH exposure has far wider consequences on aspects of learning, memory, and cognition. Acute or

*Correspondence: Dr R Ito, Department of Experimental Psychology, University of Oxford, South Parks Road, Oxford OXI 3UD, UK, Tel: +44 I865 27/377, Fax: + 441865 310447, E-mail: rutsuko.ito@ psy.ox.ac.uk

Received 14 October 2009; revised 6 January 2010; accepted 25 January 2010 repeated exposure to AMPH in animals facilitates many forms of appetitive learning, including the acquisition of a Pavlovian approach to, and instrumental responding for, a reward-associated cue (Harmer and Phillips, 1998; Taylor and Jentsch, 2001), and habit learning (Nelson and Killcross, 2006; Nordquist et al, 2007). Repeated infusions of AMPH directly into the nucleus accumbens (NAc) enhance the acquisition of a novel instrumental responding for response-contingent conditioned reinforcers (Taylor and Robbins, 1984; Taylor and Horger, 1999) and responsenoncontingent food cues (Wyvell and Berridge, 2000), highlighting the importance of elevated mesolimbic dopamine in mediating these effects.

In contrast, a sensitizing regimen of AMPH treatment can cause cognitive disturbances reminiscent of symptoms of schizophrenia (Castner and Goldman-Rakic, 2003). Impaired performance in spatial working memory with a concomitant decrease in DA turnover in the dorsolateral prefrontal cortex and caudate putamen has been reported in primates pretreated with AMPH (Castner et al, 2005). Escalating doses of AMPH in rats also impair visual attentional task performance; a deficit that was reversible 
with the application of a D1 receptor agonist into the medial prefrontal cortex (mPFC; Fletcher et al, 2007). Indeed, AMPH withdrawal is often associated with a decreased dopaminergic neurotransmission in the prefrontal cortex (Paulson and Robinson, 1995; Pierce and Kalivas, 1997; Castner et al, 2005).

NAc and mPFC are crucial components of a wider cortico-limbic-striatal circuitry that regulates the control of adaptive behavior by behaviorally significant stimuli (Cardinal et al, 2002). Both regions receive dopaminergic inputs from the ventral tegmental area (VTA) that overlap with converging glutamatergic inputs from key limbic structures, namely, the hippocampus (HPC) and amygdala (Pennartz et al, 1994; Mulder et al, 1998; French and Totterdell, 2003), implicated in spatial/contextual learning and the formation of associations between discrete cues and behaviorally salient events, respectively (O'Keefe and Nadel, 1978; Morris et al, 1982; Phillips and LeDoux, 1992; Burns et al, 1993; Ito et al, 2006). Much evidence suggests that these limbic inputs compete for control over appetitive behavior (White and McDonald, 1993; Ito et al, 2006). The objective of this study was thus to test the hypothesis that repeated AMPH exposure causes dysregulation in the balance of control over appetitive behavior by the two competing learning and memory systems, using two tasks: (1) a novel concurrent cue and spatial conditioning task in which spatial cues and a nonspatial elemental cue were in direct competition with one another for associative strength, and the rate of acquisition monitored by conditioned preference tests; (2) a parallel conditional cue and spatial conditioning task in which the presence or absence of specific floor inserts in the start arm functioned as a conditional cue in determining which of the two goal arms would be rewarded. We present novel findings that AMPH sensitization alters the balance of limbic information processing, preferentially enhancing hippocampal control under circumstances in which HPC-dependent and basolateral amygdala (BLA)-dependent information are directly in competition with one another for control over appetitive behavior, while suppressing BLA control over appetitive behavior.

\section{METHODS}

The subjects were 80 female C57BL/6 mice (Harlan, UK) weighing between 18 and $22 \mathrm{~g}$ at the time of surgery or drug treatment. They were group housed (6) in a room maintained at a temperature of $21^{\circ} \mathrm{C}$ under a $12 \mathrm{~h}$ light/ dark cycle (lights on at $0700 \mathrm{~h}$ ). Water was available ad libitum, but before the start of behavioral testing, food (laboratory chow, Purina) was restricted to $2 \mathrm{~g}$ lab chow/ day, sufficient to maintain preoperative/treatment body weight and growth. All experiments were conducted during the light phase, in accordance with the United Kingdom 1986 Animals (Scientific Procedures) Act Project License No. 30/2561.

\section{Surgery}

In all surgical procedures, animals were anesthetized with isoflurane (Abbott Lab Ltd, Kent, UK), and placed in a stereotaxic frame (Kopf, USA) with the incisor bar set at $-1.0 \mathrm{~mm}$ below the interaural line. A $5 \mu \mathrm{l}$ Hamilton syringe adapted with a 34-gauge stainless steel needle was then lowered into the HPC or BLA for bilateral lesions. For HPC lesions, four injections of $0.07 \mathrm{M}$ NMDA (Sigma-Aldrich, Dorset, UK) in $0.1 \mathrm{M}$ sterile phosphate buffer (sterile $\mathrm{PB}$ ) were administered according to established methodology (Deacon et al, 2002), using the following coordinates (in $\mathrm{mm}$ from bregma): $0.1 \mu \mathrm{l}$ each at $\mathrm{AP}=+1.8,+1.3,+0.7$, $\mathrm{L}= \pm 1.5, \pm 1.8, \pm 2.4, \mathrm{~V}=-1.8,-2.0,-2.0 ; 0.15 \mu \mathrm{l}$ at $\mathrm{AP}=+0.7, \mathrm{~L}= \pm 3.1, \mathrm{~V}=-3.5$. The infusion cannula was left in place for a further $3 \mathrm{~min}$ after each infusion to allow complete diffusion of the toxin from the tip. For BLA lesions, one infusion of $0.07 \mathrm{M}$ NMDA buffered to pH7.4 using $0.1 \mathrm{M}$ sterile $\mathrm{PB}$ was made at the following coordinates: $0.1 \mu \mathrm{l}$ at $\mathrm{AP}=+2.5, \mathrm{~L}= \pm 3.25, \mathrm{DV}=-4.8$ (SS), followed by $2 \mathrm{~min}$ diffusion time. Sham control groups were treated in a manner identical to that of the lesion groups, except that they did not receive any form of infusions. After surgery, mice were allowed a recovery period of at least 7 days before behavioral testing, with food available ad libitum.

\section{Amphetamine Drug Injections}

A total of $40 \mathrm{C} 57 \mathrm{BL} / 6$ mice were assigned to three groups of 13 or 14 mice: AMPH $5 \mathrm{mg} / \mathrm{kg}$ (AMPH 5 ; $n=13$ ); АMPH $2.5 \mathrm{mg} / \mathrm{kg}$ (AMPH 2.5; $n=13$ ); and vehicle (VEH; $n=14$ ). AMPH 5 and AMPH 2.5 mice were administered seven daily injections (i.p.) of D-AMPH sulfate (at a dose of $2.5 \mathrm{mg} / \mathrm{kg}$ or $5 \mathrm{mg} / \mathrm{kg}$ ). Mice in the $\mathrm{VEH}$ group received seven daily injections (i.p.) of saline. All injections were administered in a separate room to their housing and behavior-testing environment. All mice were then given a minimum of 7 days of drug-free period before any form of behavioral testing began.

\section{Conditioned Cue and Place Preference Task}

Radial arm maze apparatus. Behavioral testing took place in a six-arm radial maze made of wood and painted gray, elevated $80 \mathrm{~cm}$ from the floor. The maze consisted of six open arms with a $1 \mathrm{~cm}$ raised edge $(60 \times 7 \mathrm{~cm})$ emanating from a central compartment, which was surrounded by a transparent perspex cylinder $(18 \mathrm{~cm}$ diameter, $30 \mathrm{~cm}$ high) with six manually operated doors allowing access to each of the arms. Stainless steel wells in which mice could be rewarded with $0.1 \mathrm{ml}$ of sweetened condensed milk were located at the end of each arm. The maze itself was placed in a large room with various extra-maze cues (stools, posters, sink), which remained in the same position for the duration of the experiment. The floor of the maze was wiped down with ethanol solution after each session to eliminate any traces of odor and the maze was rotated to varying degrees $\left(60^{\circ}, 120^{\circ}\right.$, or $\left.180^{\circ}\right)$ at the end of the testing day to minimize conditioning to intra-maze cues.

\section{Experimental Procedure}

Habituation. All mice were given one $15 \mathrm{~min}$ habituation session in which they were free to explore the whole maze. 


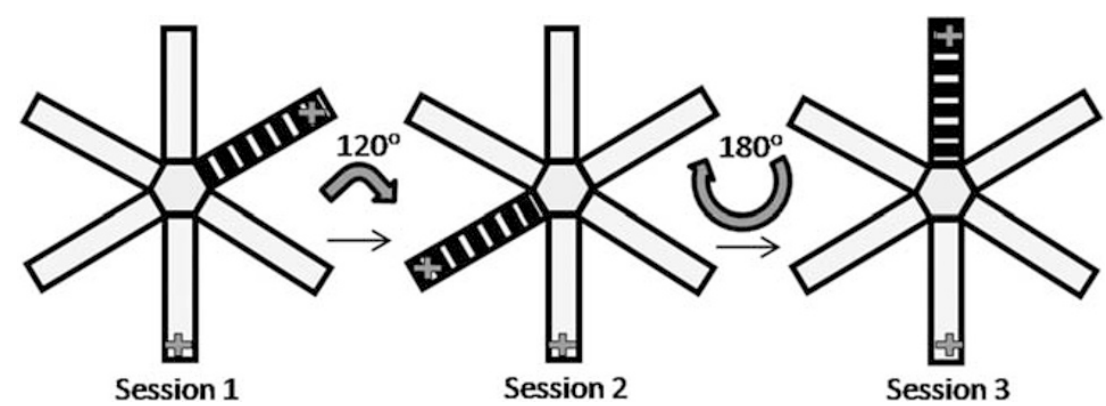

Figure I Concurrent cue and place conditioning task (conditioning sessions I-3 shown): mice were confined in each of the six arms of the radial maze for $2 \mathrm{~min}$ on each day of conditioning (+ depicts the rewarding arms, the rest of the arms were nonrewarding). The apparatus was rotated by varying degrees, and the stripy floor insert (cue) was moved to a different arm between sessions to minimize conditioning to intramaze cues. A conditioned cue and place preference test was conducted on the day after the third session (session 4). This cycle of three conditioning sessions, followed by a conditioned preference test, was repeated two more times.

Conditioning (sessions 1-3, 5-7, 9-11). Mice were given three rounds of three daily sessions of concurrent cue and place conditioning, such that they received a total of nine reward-cue and reward-place pairings (see Figure 1). For each daily session, mice were confined in each of the six arms for $3 \mathrm{~min}$, with the order of presentation of the arms randomized across sessions for each animal. They received three aliquots of $0.1 \mathrm{ml}$ condensed milk within the $3 \mathrm{~min}$ confinement period in an arm that contained a continuous striped floor insert stimulus (cue conditioning), and in an arm that was in a particular spatial location (place conditioning), but did not receive any reward in the rest of the four arms. The floor insert was moved randomly between different arms (all arms except the place arm) across each session, and the maze was rotated after each session to minimize conditioning to the arms themselves.

Conditioned cue and place preference test (session 4, 8, 12). After each round of three conditioning sessions, mice were given $5 \mathrm{~min}$ to explore the entire apparatus in the absence of any reward. Thus, a total of three preference tests were conducted for each animal. The time spent in each arm location was recorded.

\section{Conditional Cue and Spatial Learning Task}

Subjects. Subgroups of animals from experiment 1 (BLA group $n=6$; BLA sham, $n=6$; Saline, $n=6$; AMPH 2.5 $n=7$; AMPH $5 n=7$ ) were subsequently tested on the conditional cue and spatial learning task in a new room with novel spatial cues and floor inserts.

T-maze apparatus. Behavioral testing was conducted in an elevated wooden, gray-painted T-maze that consisted of a start arm $(35 \times 10 \mathrm{~cm})$ and two goal arms $(35 \times 10 \mathrm{~cm})$ (Figure 2). Specially adapted stainless steel food wells were placed at the end of both arms, comprising a small well embedded in another well half-filled with condensed milk (but inaccessible to the animal) to ensure that the animals did not solve the task on the basis of odor cues. The maze was surrounded by a $10 \mathrm{~cm}$ raised wall, and was placed in a different room to the radial maze, with a number of distinct extra-maze cues. White perspex and wire mesh floor inserts extending the whole length of the start arm were used as conditional cues, and sand paper and green felt floor inserts were used in the goal arms for the conditional cue trials.

\section{Experimental Procedure}

Habituation. Mice were allowed 4 days of $2 \mathrm{~min}$ free exploration of the T-maze apparatus and given the opportunity to collect rewards from the ends of the two goal arms.

Conditioning. Mice were trained to learn three floor insertreward contingencies (Figure 2): (1) white perspex floor insert in the start arm signaled the availability of reward ( $0.1 \mathrm{ml}$ condensed milk) in the left goal arm; (2) wire mesh insert - reward in the right goal arm; and (3) no floor insert - reward in the sand paper goal arm (but not in the green felt goal arm). The pairing of the start-arm floor insert and rewarded goal arm and the assignment of reward contingencies to goal-arm floor inserts were counterbalanced across animals, and remained constant for each mouse across sessions. The first two associations assessed spatial learning, and their successful acquisition has previously been shown to depend on the integrity of the HPC (Schmitt et al, 2004). The last association tested cue learning, and the position of the goal arm floor inserts (green felt or sand paper) was changed (right or left goal arm) from trial to trial. The mice received a total of 28 sessions of 12 trials with an intertrial interval of around $5 \mathrm{~min}$. Each session consisted of four cue learning trials, and eight spatial learning trials (four with each floor insert) presented in a pseudorandom sequence, with no more than three successive trials with the same contingencies.

\section{Locomotor Sensitization Test in AMPH-Pretreated Mice}

AMPH- or saline-pretreated mice were placed in individual transparent plastic cages $(26 \times 15 \times 17 \mathrm{~cm})$ equipped with two sets of infrared photobeams located $14 \mathrm{~cm}$ apart and $1.5 \mathrm{~cm}$ above the floor, and their locomotor activity was measured in $5 \mathrm{~min}$ time bins. At $2 \mathrm{~h}$ after the beginning of the session, all mice were given one injection of AMPH $(2.5 \mathrm{mg} / \mathrm{kg}$, i.p.) and placed back into the activity cages. Locomotor activity was then monitored for another $2 \mathrm{~h}$. 


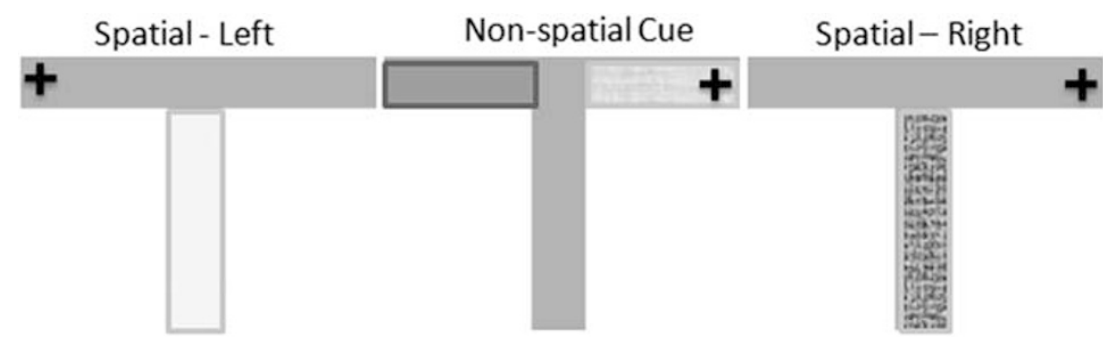

Figure 2 Parallel conditional cue and spatial learning task. Mice were trained to learn three floor insert-outcome contingencies on the basis of spatial or nonspatial cues in the goal arms. + depicts the location of the reward.

Table I Time Spent (mean \pm SEM) in Cue, Place, and Nonrewarded (NR) Arms, and Total Time Spent (mean \pm SEM) Exploring all the Arms During the Three Conditioned Cue and Place Preference Tests in Mice with Hippocampus (HPC), Basolateral Amygdala (BLA), or Sham Lesions, and in Mice Pretreated with Saline or 2 Doses of Amphetamine (AMPH)

\begin{tabular}{|c|c|c|c|c|c|c|c|}
\hline & Arm & HPC & BLA & Sham & Saline & AMPH (2.5 mg/kg) & AMPH (5 mg/kg) \\
\hline \multirow{2}{*}{ TEST I } & Cue & $78.8 \pm 4.6$ & $26.3 \pm 4.6 * *$ & $53.9 \pm 6.1$ & $46.6 \pm 4.8$ & $34.3 \pm 3.9 *$ & $30.9 \pm 3.0 * *$ \\
\hline & NR arms & $30.6 \pm 4.3$ & $18.5 \pm 3.7$ & $18.9 \pm 3.5$ & $17.1 \pm 2.1$ & $|6| \pm 2.0$. & $19.6 \pm 2.1$ \\
\hline \multirow[t]{2}{*}{ TEST 2} & Total time & $197.1 \pm 11.3$ & $161.7 \pm 14.4$ & $183.4 \pm 7.5$ & $\mid 44.0 \pm 8.5$ & $174.4 \pm 8.73 * *$ & $156.8 \pm 8.3$ \\
\hline & NR arms & $26.0 \pm 4.6$ & $19.1 \pm 3.6$ & $21.2 \pm 3.0$ & $15.7 \pm 2.0$ & $20.5 \pm 3.3$ & $20.8 \pm 2.5$ \\
\hline \multirow[t]{4}{*}{ TEST 3} & Total time & $200.2 \pm 10.9$ & $121 \pm 9.7 * * *$ & $|87.5 \pm 1| .8$ & $165.3 \pm 9.0$ & $197.7 \pm 13.1 *$ & $168.7 \pm 8.7$ \\
\hline & Cue & $75.2 \pm 5.5$ & $34.4 \pm 3.8$ & $63.6 \pm 6.9$ & $47.0 \pm 3.4$ & $39.9 \pm 5.3$ & $40.5 \pm 3.9$ \\
\hline & Place & $32.1 \pm 4.8^{*}$ & $36.9 \pm 6.0$ & $47.1 \pm 5.6$ & $56.5 \pm 7.1$ & $83.4 \pm 14.3$ & $48.7 \pm 6.0$ \\
\hline & NR arms & $23.3 \pm 3.9$ & $12.4 \pm 2.6$ & $18.7 \pm 2.8$ & $14.0 \pm 2.3$ & $18.9 \pm 3.1$ & $17.8 \pm 2.7$ \\
\hline
\end{tabular}

Note that the time shown for the NR arms represents the pooled mean of the time spent in all four nonrewarding arms for each animal, and thus may not be truly representative of the commonly observed unequal distribution of the actual time spent in the four arms. Asterisks denote significant differences in the times spent $(* * P<0.01 ; * P<0.05)$ from the control groups (sham or saline). Statistical tests on the time spent in the cue/place arms were conducted only for test sessions in which the total time spent in the apparatus was not significantly different between groups.

\section{Histological Procedure}

All BLA and HPC and sham-lesioned mice were anesthetized with sodium pentobarbitone $(0.25 \mathrm{ml} / \mathrm{animal}, 200 \mathrm{mg} / \mathrm{ml}$ Euthatal, Rhone Merieux, UK) and perfused intracardially through the ascending aorta with $0.01 \mathrm{M}$ phosphate-buffered saline, followed by $10 \%$ formalin saline. Brains were then removed, stored in $10 \%$ formalin, and transferred to a $30 \%$ sucrose cryoprotectant solution on the day before sectioning. Coronal sections $(50 \mu \mathrm{m})$ of the brain were cut using a freezing microtome and then stained with cresyl violet.

\section{Data Analysis}

All data were analyzed using the SPSS statistical package version 15.0 (SPSS, Chicago, IL). Data generated for each test session in the conditioned preference task consisted of the absolute time spent in each of the six arms of the radial maze within $5 \mathrm{~min}$ (see Table 1). These times were subsequently converted into 'discrimination ratios', which were calculated as the 'time spent in each arm' divided by 'time spent in all the arms' to control for differences in the degree of exploration between mice within, as well as between, groups. Repeated measures analysis of variance (ANOVA) was thus applied to the discrimination ratios, with lesion or treatment group as the between-subjects factor and test (three levels) and/or arms (three levels; CUE, PLACE, NR) as the within-subjects factor(s). Further ANOVAs and post hoc tests including Dunnett's test (for comparisons of treatment/lesion group performance with sham group performance) and one sample $t$-test (to evaluate performance above chance level) were conducted on confirmation of significant interactions. However, in cases in which there were no significant differences in the total time spent exploring the arms in conditioned preference tests between treatment/lesion groups, selective ANOVAs were also conducted on the absolute time spent in the cue and place arms, with lesion or treatment group as the between-subject factor and arms (cue $v s$ place) as the within-subject factor. For locomotor sensitization tests, repeated measures ANOVA were conducted with bins of 5 min and pre- and post-AMPH challenge as within-subject factors, and treatment group as the between-subjects factor. Furthermore, a Spearman's correlation analysis between the magnitude of locomotor activity change following an AMPH 


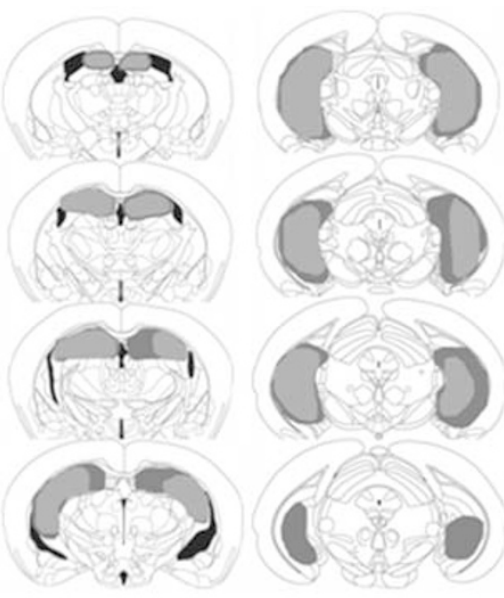

HPC
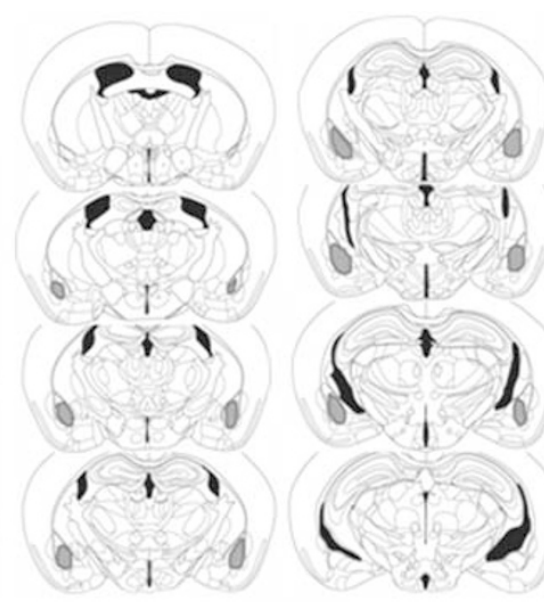

BLA

Figure 3 Schematic representation of NMDA lesions of the hippocampus (left) and basolateral amygdala (right) in mice. Areas shaded in gray and black represent the largest and smallest extent of neuronal damage in a single animal, respectively.

challenge (calculated as (mean of three bins of baseline activity) - (mean of three bins of peak activity level after $\mathrm{AMPH}$ ) for each animal), and the performance in the first test (cue and place preference discrimination ratio) was conducted. Data from the conditional cue and spatial learning task were expressed as the mean percentage of correct responses in blocks of eight trials for the conditional cue learning, and in blocks of 16 trials for the conditional spatial task, and were subjected to repeated measures ANOVA with block as the within-subject factor and treatment or lesion groups as a between-subject factor.

\section{RESULTS}

\section{Lesion Assessment}

The extent of the excitotoxic lesions of the HPC and BLA is shown schematically in Figure 3, based on Paxinos and Franklin's stereotaxic atlas of the mouse brain (2001). Excitotoxic lesions of the HPC induced by NMDA infusions consistently extended rostrally from -0.94 to $-3.80 \mathrm{~mm}$ posterior to the bregma, encompassing all the hippocampal subfields and dentate gyrus of the dorsal and ventral HPC. All HPC-lesioned mice $(n=12)$ were therefore included in data analyses.

Excitotoxic lesions of the BLA induced by NMDA resulted in significant neuronal damage to the basal amygdaloid nucleus and to the lateral nucleus of amygdala, typically extending from -0.94 to $-2.06 \mathrm{~mm}$ posterior to bregma, while sparing the central nucleus and medial nucleus of the amygdala. Three mice were excluded from data analysis on the basis of bilateral damage extending into the central nucleus of the amygdala; hence the final group consisted of nine BLA-lesioned mice.

\section{Effects of BLA and HPC Lesions on Rates of Cue and Place Learning}

Acquisition of cue and place learning in mice with BLA, HPC, and sham lesions is shown in Figure 4. For increased clarity of viewing differential rates of cue and place learning, acquisition is expressed as the mean performance above (or below) the chance level discrimination ratio (1/6) for the cue arm, place arm, and nonrewarded arms (mean performance in four nonrewarded arms after confirmation of no significant differences in the mean discrimination ratios of each of the four arms) for each of the three tests.

Sham-lesioned mice showed significant preference for the cue arm over the place arm and nonrewarding arms in the first test $(\mathrm{F}(2,24)=24.87, p<0.0001)$, showing that three conditioning sessions were sufficient to establish the cuereward association (significantly above chance level: $t=6.10, p<0.0001)$. In contrast, conditioned preference for the place arm took longer to emerge, reaching a significant level of preference above chance only in test 3 (after nine conditioning sessions: $t=4.90, p<0.001$; test 2: $t=1.97, p=0.07)$. This pattern of acquisition of place learning in the sham group was confirmed by a significant effect of test using repeated measures one-way ANOVA $(\mathrm{F}(2,24)=4.92, p<0.016)$.

Overall three-way ANOVA conducted on discrimination ratio data across the three test sessions for all lesion groups revealed a significant arm $\times$ lesion group interaction $(\mathrm{F}(4,62)=9.48, p<0.0001)$ and a near significant lesion effect $(\mathrm{F}(2,31)=2.89, \quad p=0.07)$, as well as significant main effects of arm $(F(2,62)=74.75, p<0.0001)$ and test $(\mathrm{F}(2,62)=11.65, \quad p<0.0001)$, and significant arm $\times$ test interaction $(F(4,124)=5.45, p<0.001)$. Separate ANOVAs on the performance of the BLA and HPC groups for cue learning and place learning revealed that BLA-lesioned mice showed significantly reduced preference for the cue arm compared with the overall level of preference shown by sham-operated mice (lesion effect, $F(1,20)=11.12$, $p<0.003$ ), but a level of place preference that was not different from the sham level of performance (no lesion effect; $\mathrm{F}(1,20)=1.50$, NS). Post hoc analyses revealed that the level of preference for the cue arm shown by BLA-lesioned mice was significantly lower than that of the sham group in test $1(p<0.001)$, and this was supported by 


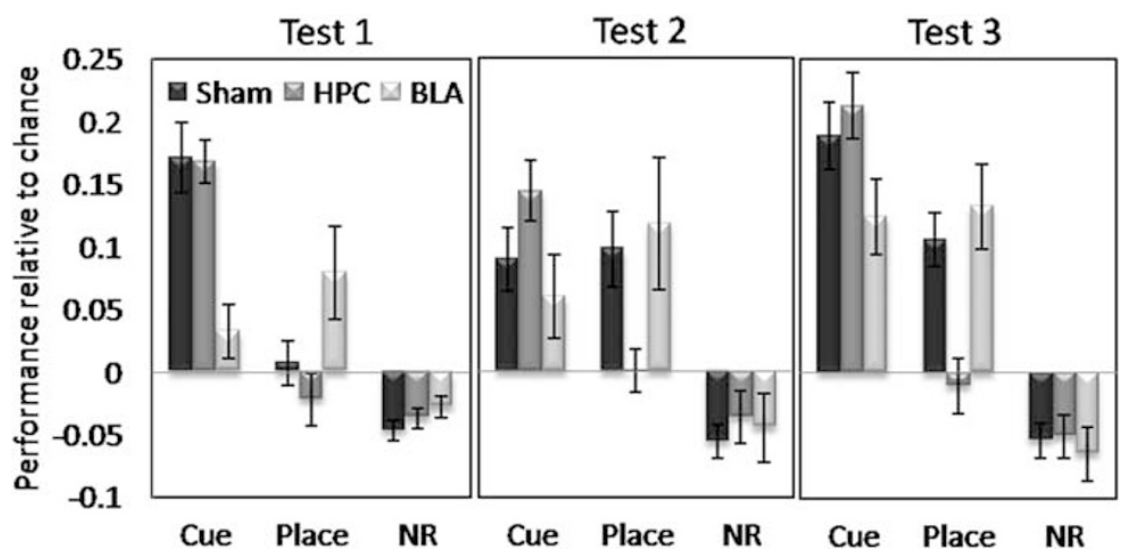

Figure 4 Conditioned cue and place preference tests ( $5 \mathrm{~min}$ ) for sham-operated controls, as well as for HPC and BLA lesion groups, expressed as the mean \pm SEM performance above or below chance discrimination ratio level $(0.16666)$ for the cue arm, place arm and nonrewarding (NR) arms.

the fact that neither of the discrimination ratios for the cue arm in tests 1 and 2 was significantly different from the chance level in the BLA group (test 1: $t=1.46, \mathrm{NS}$; test 2: $t=1.82$, NS). BLA-lesioned mice did, however, reach a level of cue preference above chance after nine sessions of conditioning (test 3: $t=4.215, p<0.003$ ).

There was also a trend toward significantly increased levels of place-arm preference in the first test in the BLA group compared with that in the sham group (one-way ANOVA on all three groups for place in test 1: $\mathrm{F}(2,33)=3.73, p<0.035$, post hoc analysis between BLA and sham groups: $p=0.08$ ); however, the actual level of place-arm preference shown by the BLA group did not reach a level significantly above chance till test 3 (test 1: $t=2.13, p=0.066$; test $2: t=2.23, p=0.056, t=4.25$, $p<0.0003)$, as with the sham group performance.

HPC-lesioned mice showed the opposite pattern of results, with a significantly reduced overall level of preference for the place arm compared with the shamoperated mice across all tests (lesion effect: $\mathrm{F}(1,23)=12.76$, $p<0.002$ ), but not for the cue arm (no lesion effect: $F(1$, $23)=1.16$, NS). Post hoc analyses revealed that the level of preference for the place arm in the HPC group was significantly lower than that in the sham group in test $3(p<0.003)$. A significant difference between place preference performance between the HPC and sham groups in test 2 was also confirmed by post hoc analysis $(p<0.038)$. As with the sham-lesioned group, HPC-lesioned mice showed significant preference for the cue arm in test $1(t=9.62, p<0.00001)$, and this level of performance significantly above chance was maintained in tests 2 and 3 (test 2: $t=5.90, p<0.0001$; test $3: t=7.98$, $p<0.00001)$.

In summary, BLA-lesioned mice were significantly slower to acquire cue learning, only achieving a level of conditioned cue preference above chance level after nine conditioning sessions, compared with the three sessions required for sham-lesioned mice and HPC-lesioned mice. In contrast, HPC-lesioned mice were significantly impaired in acquiring place learning, but not cue learning, with no evidence of place preference even after nine conditioning sessions.

\section{Effect of Repeated AMPH PreTreatment on Rates of Cue and Place Learning}

Acquisition of cue and place learning in mice pretreated with saline (VEH) or AMPH $(2.5 \mathrm{mg} / \mathrm{kg}$ or $5 \mathrm{mg} / \mathrm{kg})$ is shown in Figure 5. Saline-pretreated mice exhibited cuearm preference over the place arm and nonrewarding arms $(\mathrm{F}(2,24)=13.48, p<0.0001)$, which was also significantly above chance level in test $1(t=5.67, p<0.0001)$, and which remained significantly above chance in subsequent tests (test 2: $t=6.25, p<0.0001$; test $3: t=5.18, p<0.0002$ ). Significant preference for the place arm in the saline treatment group was apparent in test $2(t=6.44, p<0.0001)$ and test $3(t=5.68, p<0.0001)$.

Overall three-way ANOVA conducted on discrimination ratio data across the three test sessions for all treatment groups revealed a significant arm $\times$ treatment group interaction $(\mathrm{F}(4,72)=7.28, p<0.0001)$, as well as significant main effects of arm $(\mathrm{F}(2,72)=197.63, p<0.0001)$ and test $(\mathrm{F}(2,72)=11.34, p<0.0001)$, and significant arm $\times$ test interaction $(F(4,144)=8.03, p<0.00001)$. Separate ANOVAs on the performance of the AMPH-treated groups compared with saline-treated groups for cue learning revealed that both the AMPH 2.5- and AMPH 5-treated groups showed significantly reduced preference for the cue arm compared with the overall level of preference shown by saline-treated mice across all tests (AMPH 2.5 treatment effect: $\mathrm{F}(1,25)=15.51, p<0.001$; AMPH 5 treatment effect: $\mathrm{F}(1,25)=18.39, p<0.0001)$. Dunnett's tests revealed the level of cue preference to be significantly different (lower) to the saline-treated level of performance in tests $1(p<0.005)$ and $2(p<0.05)$ for the AMPH 5 group, and for test 3 $(p<0.05)$ for the Amph 2.5 group. However, ANOVAs conducted on the absolute times spent in the cue and place arms in test 1, on confirmation of no significant difference in the overall exploratory time between treatment groups $(\mathrm{F}(2,39)=0.004, p=1.0)$, revealed that there was a significant arm $\times$ treatment interaction for both AMPH groups when compared with the saline group (AMPH 2.5: $\mathrm{F}(1,25)=15.5, \quad p<0.001$; AMPH 5: $\mathrm{F}(1,25)=15.67$, $p<0.001)$. Subsequent Dunnett's tests conducted on the absolute times spent in the cue arm in test 1 confirmed that 


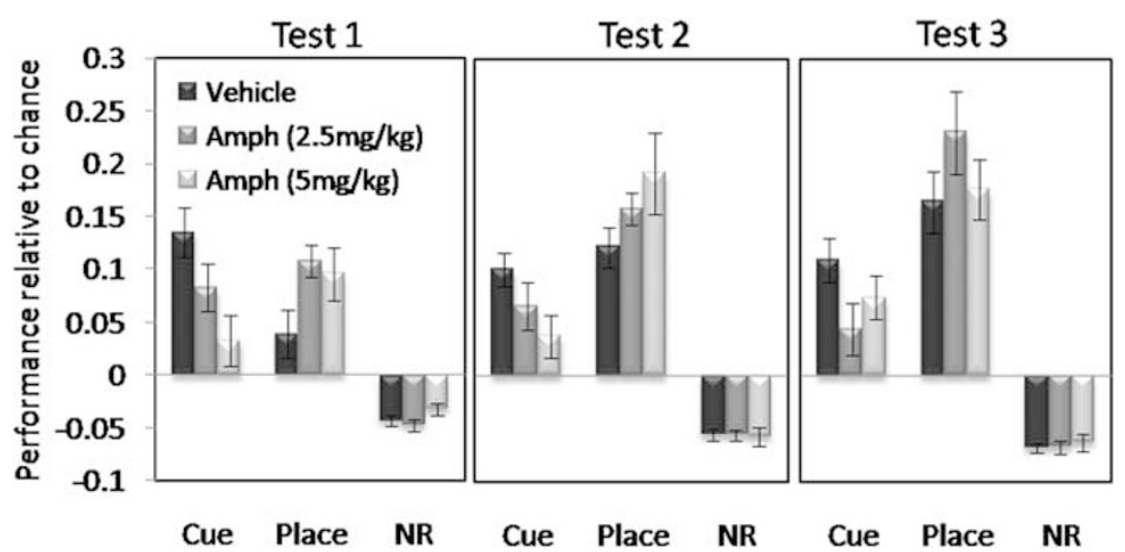

Figure 5 Conditioned cue and place preference tests $(5 \mathrm{~min})$ for saline-pretreated controls, AMPH 2.5- and AMPH 5-pretreated mice expressed as the mean \pm SEM performance above or below the chance discrimination ratio level $(0.16666)$ for the cue arm, place arm and nonrewarding (NR) arms.

mice in both the AMPH 2.5 and AMPH 5 groups spent significantly less time in the cue arm than mice in the saline group in test $1(p<0.05)$, indicating attenuated cue learning even in test 1 in the AMPH 2.5 group.

ANOVA comparing place-arm preference between treatment groups across three tests revealed that the strength of place preference increased across the three tests in all groups $(\mathrm{F}(2,74)=13.66, p<0.0001)$, and that there was a significant effect of AMPH treatment in the degree of place preference that was expressed $(\mathrm{F}(2,37)=3.67, p<0.035)$. Both AMPH groups showed place preference significantly above chance level in test 1 (AMPH 2.5: $t=6.25, p<0.0001$; AMPH 5: $t=3.84, p<0.002$ ), which was also significantly different from the level of place preference seen in salinetreated mice in the AMPH 2.5 group (Dunnett's $p<0.05$ ).

In summary, mice that had received repeated AMPH showed significantly reduced conditioned cue preference across the three tests. In contrast, both AMPH-pretreated groups showed facilitation of place learning, with significant establishment of place preference after three conditioning sessions, compared with the six sessions required by the saline-treated group.

\section{Effect of BLA Lesions on Conditional Cue and Spatial Learning}

Acquisition curves of conditional cue and spatial learning in BLA-lesioned and sham-operated mice are shown in Figure 6. All mice were successful in acquiring conditional associations between the absence of a floor insert in the start arm and the availability of reward in the goal arm with a specific cue (block effect: $F(13,130)=7.64, p<0.0001$ ). However, BLA-lesioned mice showed a significantly lower level of correct performance throughout training, compared with sham-group performance (lesion effect: $\mathrm{F}(1,10)=13$, $p<0.005)$. In contrast, there were no differences in the performance of BLA-lesioned mice and sham-operated controls (no lesion effect: $\mathrm{F}(1,10)=0.58, p=0.46$ ) in the ability to use start arm floor inserts as a conditional cue in solving the spatial version of the task (block effect: $\mathrm{F}(15$, $150)=5.39, p<0.0001)$.
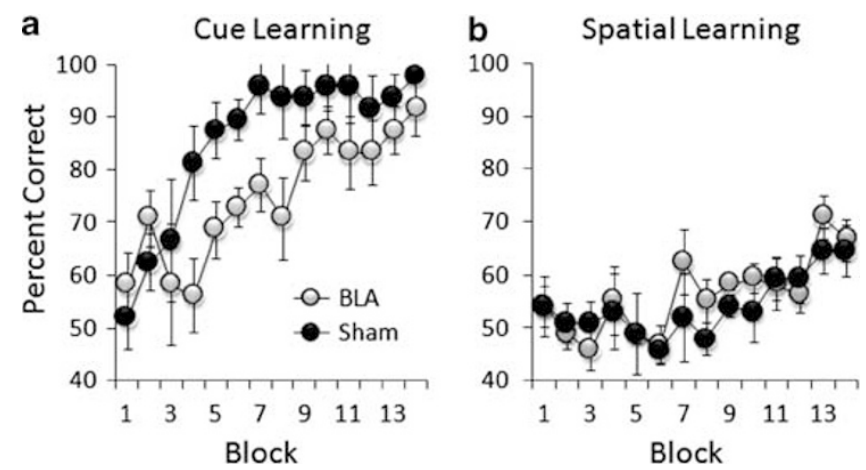

Figure 6 Performance of conditional cue (a) and spatial learning (b) in BLA-lesioned and sham-operated control mice expressed as the mean \pm SEM percentage of correct trials in blocks of eight trials in conditional cue learning, and in blocks of 16 trials in conditional spatial learning.

\section{Effect of AMPH Exposure on Conditional Cue and Spatial Learning}

Acquisition curves of conditional cue and spatial learning in saline- and AMPH-pretreated mice are shown in Figure 7. While all mice acquired the cue version of the conditional task $(F(13,221)=13.22, p<0.0001)$, the overall levels of correct responses in both the AMPH 2.5 and AMPH 5 groups were significantly lower than those achieved by the sham group (treatment effect with all groups: $\mathrm{F}(2$, $17)=22.88, \quad p<0.0001 ; \quad$ AMPH $2.5 \quad v s$ saline: $\mathrm{F}(1$, $11)=62.05, p<0.0001$; AMPH $5 v s$ saline: $\mathrm{F}(1,11)=15.50$, $p<0.01)$. All saline- and AMPH-pretreated groups were able to solve the spatial version of the conditional learning task (block effect: $\mathrm{F}(13,221)=8.21, p<0.0001$; saline: $\mathrm{F}(13$, $65)=5.22, p<0.0001$; AMPH 2.5: $\mathrm{F}(13,78)=2.63, p<0.01$; AMPH 5: $\mathrm{F}(2,45)=2.45, p<0.01)$ and the performance between saline- and AMPH-pretreated groups did not differ (no treatment effect: AMPH 2.5 vs saline, $\mathrm{F}(1,11)=0.31$, $p=0.59$; AMPH $5 v s$ saline, $\mathrm{F}(1,11)=2.34, p=0.15)$.

In summary, both BLA-lesioned and AMPH-pretreated mice were significantly attenuated in the acquisition of conditional cue learning, but not in the acquisition of a spatial version of the same task. 

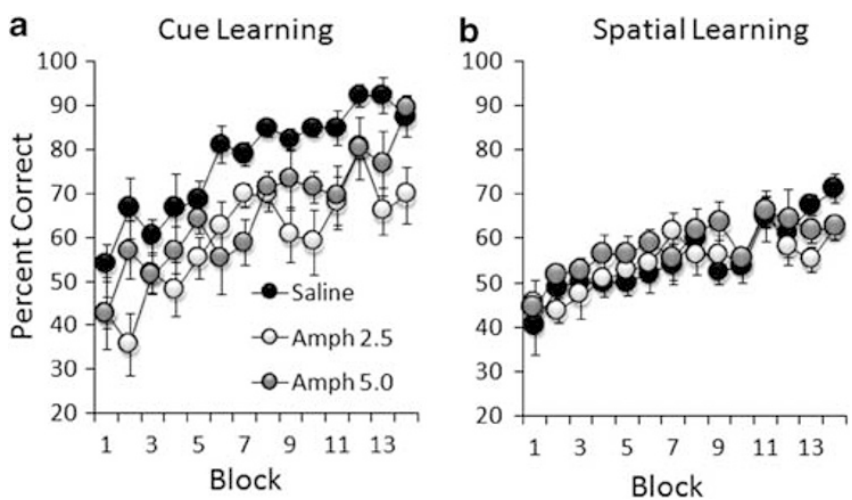

Figure 7 Performance of conditional cue (a) and spatial learning (b) in saline- and amphetamine-pretreated (AMPH $2.5 \mathrm{mg} / \mathrm{kg}$ and $\mathrm{AMPH} 5 \mathrm{mg} / \mathrm{kg}$ groups) mice, expressed as the mean \pm SEM percentage of correct trials in blocks of 8 trials in conditional cue learning, and in blocks of 16 trials in conditional spatial learning.

\section{Locomotor Response to AMPH Challenge}

Overall three-way ANOVA conducted on the changes in the mean number of beam broken before, and following a single AMPH challenge (see Figure 8), revealed a significant effect of the challenge on locomotor activity in all groups $(\mathrm{F}(1$, $35)=134.5, p<0.0001)$ and AMPH challenge $\times$ treatment group interaction $(\mathrm{F}(2,35)=10.48, p<0.0001)$, as well as a significant difference in the overall level of locomotor activity between groups $(\mathrm{F}(2,35)=4.78, p<0.01)$. Selective analyses on the baseline locomotor activity (bins 1-24) showed that there was a significant difference in the activity levels between groups $(\mathrm{F}(2,36)=4.11, p<0.025)$ that was due to the AMPH 5 group showing much lower overall activity levels compared with saline-treated rats in this period $(p<0.01)$. All groups did, nevertheless, show reduced levels of activity before the AMPH challenge $(\mathrm{F}(23,828)=105.0, \quad p<0.00001)$. Selective analyses on locomotor activity in the period following the AMPH challenge (bins 25-48) revealed a significant difference in activity levels between treatment groups $(\mathrm{F}(2,35)=7.32$, $p<0.002)$ and a significant group $\times$ bin interaction $(\mathrm{F}(46$, $828)=2.08, p<0.00001)$. Post hoc analyses attributed these effects to significantly enhanced increase in locomotor activity (locomotor sensitization) in both AMPH 2.5 and AMPH 5 groups compared with saline-treated mice (AMPH $2.5 ; p<0.017$, AMPH $5 ; p<0.001)$. Analyses comparing activity levels between the AMPH 2.5 and AMPH 5 groups showed that there was no significant difference between the overall levels in increased activity between groups after an AMPH challenge $(F(1,23)=0.71, N S)$, but a significant bin $\times$ treatment interaction $(\mathrm{F}(23,529)=1.71, p<0.02)$, reflecting the fact that mice in the AMPH 5 group showed sustained increase in locomotor activity at the end of the session, by which time locomotor activity in the AMPH 2.5 group returned to levels similar to those of saline-treated mice.

\section{Correlative Analyses between Performance in Test 1 and Degree of Locomotor Sensitization}

Pearson's correlation analyses between the degree of locomotor sensitization shown by each AMPH-pretreated

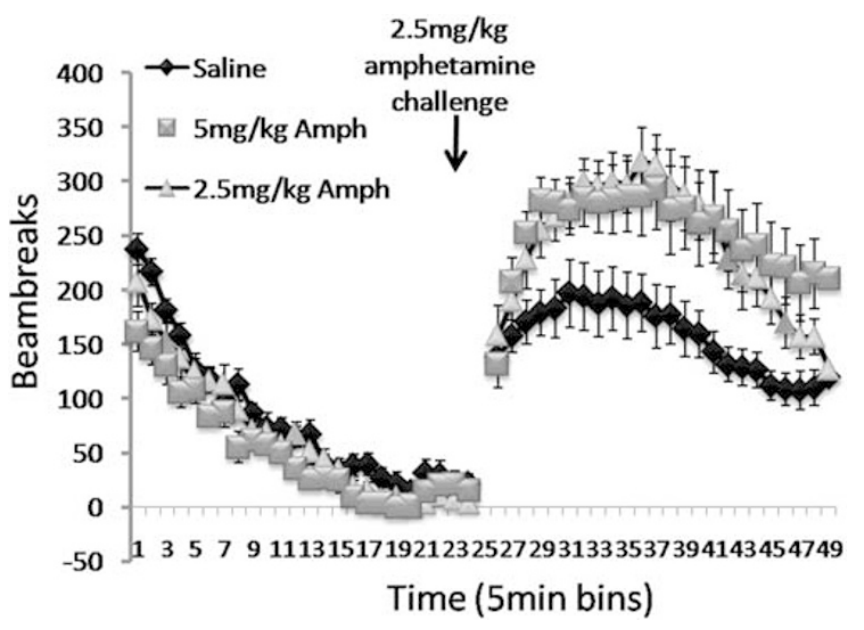

Figure 8 Locomotor sensitization test, showing mean \pm SEM locomotor beam breaks in $5 \mathrm{~min}$ bins before and after an AMPH challenge $(2.5 \mathrm{mg} / \mathrm{kg})$ for saline-pretreated controls, as well as for AMPH 2.5- and AMPH 5 -pretreated groups.
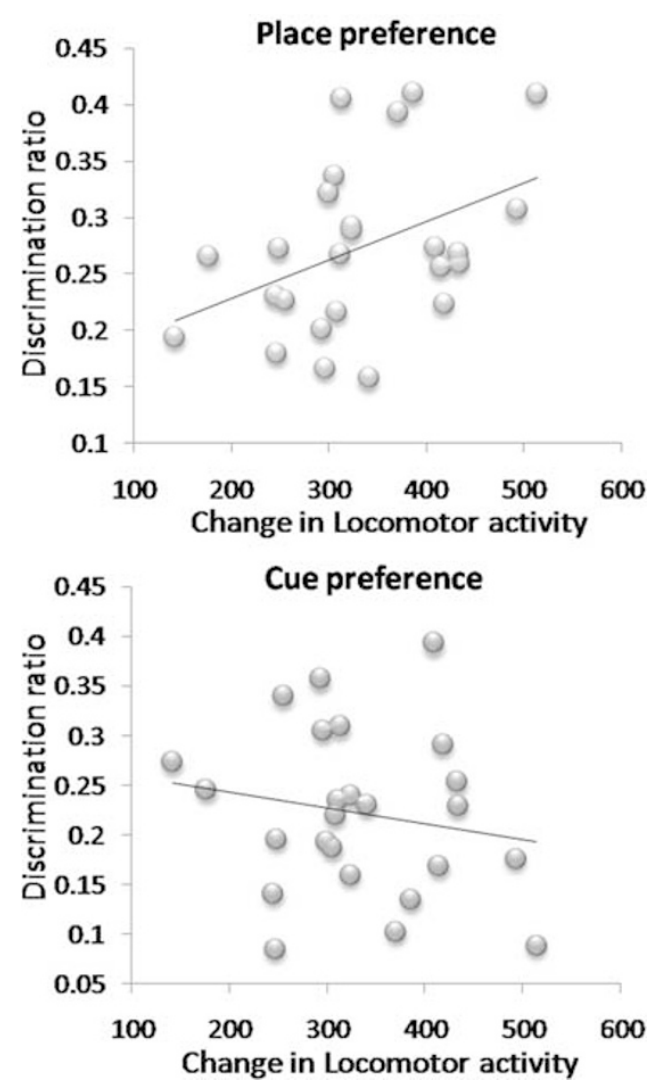

Figure 9 Correlation between performance in the first conditioned cue and place preference test (discrimination ratios) and degree of locomotor sensitization shown by each animal in the AMPH groups.

mouse and their cue and place preference performance in test 1 (the test most sensitive to differential rates of conditioning between cue and place learning, see Figure 9) showed that there was a significant positive correlation between the magnitude of locomotor sensitization and the degree of place preference $(r=0.42, p<0.038)$, but not cue 
preference $(r=-0.17, p=0.40)$. The same analyses in saline-pretreated mice did not yield any significant correlations (place $v s$ locomotor activity increase: $r=0.11$, $p=0.70$; cue $v s$ locomotor activity increase: $r=0.008$, $p=0.98)$.

\section{DISCUSSION}

This study provides novel and important findings that a sensitizing regimen of $\mathrm{AMPH}$ has selective modulatory effects on limbic information processing, enhancing place conditioning that is dependent on the integrity of the HPC while attenuating cue conditioning that is dependent on the integrity of the BLA, specifically under conditions in which the two forms of associative information compete for control over appetitive behavior. However, when HPCdependent and BLA-dependent learning occur in parallel, AMPH exposure causes attenuation of cue learning in the absence of facilitation of spatial learning. The facilitation of place conditioning showed a significant positive correlation with the degree of locomotor sensitization shown by each animal, indicating the commonality between the neural substrates of the two phenomena. These findings highlight the possible significance of the dopamine system in regulating the balance of information processing between learning and memory systems, and how disruption to this regulation could lead to manifestations of the behavioral abnormalities associated with schizophrenia and addiction.

\section{Acquisition of Cue and Spatial Learning is BLA- and HPC Dependent}

Data from control lesion and saline-pretreated mice revealed that under conditions in which elemental cues explicitly compete for associative control over appetitive behavior, elemental cues have predominant control early in training. Spatial cues then begin to have equal control over preference behavior after further conditioning sessions. Selective excitotoxic lesions of the mouse HPC caused a marked deviation from this acquisition pattern, abolishing the contribution of conditioned spatial cues in guiding preference behavior, consistent with its well-established role in spatial learning in rats and mice alike (O'Keefe and Nadel, 1978; Morris et al, 1982; Cho et al, 1999; Deacon et al, 2002), and conditioned place preference in rats (Ferbinteanu and McDonald, 2001; Ito et al, 2006). In contrast, selective excitotoxic lesions of the mouse BLA impeded the ability of a conditioned discrete cue to guide preference behavior, consistent with previous studies showing BLA lesion-induced deficits in conditioned cue preference (Everitt et al, 1991; Ito et al, 2006) and similar paradigms involving the acquisition of a conditioned discriminative approach behavior toward a CS signaling availability of sucrose in rats (Burns et al, 1993). The selective sensitivity of the conditioned cue and place preference tests to HPC and BLA lesions, respectively, makes it highly likely that the expression of preference for the cue arm or place arm is a result of acquired appetitive learning, rather than approach behavior elicited by inherent activational properties of the stimuli.
Successful performance of the conditional T-maze task depends on making correct behavioral choices on the basis of trial-specific information (occasion setting stimulus) presented in the start arm, which in turn depends on the retrieval of appropriate discrete cue-reward association (in cue trials) and place-reward association (in spatial trials). Vehicle mice and sham-operated controls showed an incremental acquisition pattern similar to that of the conditioned cue and place preference task, acquiring the cue version at a markedly faster rate than the spatial version of the task. Excitotoxic lesions of HPC in mice have been previously shown to impair the spatial version of this task (Schmitt et al, 2004), which was attributed to an impairment in a spatial-temporal tagging or encoding mechanism. Excitotoxic lesions of the BLA in this study attenuated the cue version of the task, but not the spatial version of the task, again supporting the idea that the BLA is selectively involved in the processing of elemental cue information, as opposed to spatial information.

The nature of the effects of BLA lesions on both conditioned cue preference and conditional cue learning here was transient, with the effects being most debilitating in the early part of acquisition. Similarly, a slowed but not abolished acquisition of discrete cue conditioning has been previously reported with BLA lesions (Burns et al, 1993; Ito et al, 2006). These findings raise the possibility that other associative mechanisms mediated by neural substrates outside of the BLA can also subserve this form of learning, the most likely candidate being the dorsal striatal-mediated stimulus-response mechanism (Packard and Knowlton, 2002). The involvement of the same stimulus-response mechanism in the successful performance of the conditional spatial learning cannot be ruled out completely. Nevertheless, the fact that HPC-lesioned mice show chance level (50\%) performance in conditional spatial learning that persists throughout the course of training (Schmitt et al, 2004) undoubtedly indicates a strong HPC contribution to the acquisition of the task.

\section{Effect of Repeated AMPH on Acquisition of Cue Learning}

Repeated AMPH exposure led to a marked change in the acquisition patterns of conditioned cue and place preference with a significant attenuation of conditioned cue preference that resembled the effects of BLA lesions, and a concomitant enhancement of HPC-dependent place preference. BLA-dependent cue learning in the conditional cue and spatial learning task was also attenuated in AMPHpretreated mice, although in this task, there was no concomitant facilitation of conditional spatial learning. The clear attenuation of cue learning in this study is somewhat surprising, given previous findings showing that a history of repeated AMPH facilitates the acquisition of Pavlovian discriminative approach behavior (Taylor and Jentsch, 2001), which is to some extent dependent on the integrity of the BLA (Burns et al, 1993) and the mesoamygdaloid dopamine system (although an effect of posttraining DA manipulations; Hitchcott et al, 1997). However, what is apparent is that repeated drug exposure leads to substantial alterations in BLA function, and the nature or direction of drug-induced changes in 
BLA-mediated behaviors may depend on the extent to which the functions of other brain regions that are closely connected with the BLA are affected. Thus, a recent study found that repeated cocaine pretreatment caused BLA neurons to persistently respond to outdated associative cue information during reversal learning of odor cue-go, no go discriminations, previously shown to be dependent on the integrity of the orbito-frontal cortex (Stalkaner et al, 2007). Such inflexibility in associative encoding in the BLA was observed in the absence of an actual deficit in reversal learning following lesions of the BLA, indicating that, although the BLA itself is not necessary for this process, its altered function after repeated cocaine exposure can still have debilitating effects on processes that depend on other brain structures with which it is connected.

\section{Neural Mechanism of Attenuated BLA Control Over Appetitive Behavior}

There is much evidence pointing to the idea that the attenuation of BLA control over appetitive behavior in this study is a consequence of altered meso-amygdaloid DA transmission following repeated AMPH exposure, which in turn affects meso-accumbens DA transmission. Thus, after repeated AMPH treatment, DA response in the amygdala to a subsequent AMPH challenge is augmented (Harmer et al, 1997), and the disruption of DA terminals in the amygdala prevents the development of behavioral sensitization induced by both systemic and intra-VTA AMPH pretreatment (Bjijou et al, 2002). It has been suggested that there is an inverse relationship between DA in the BLA and NAC (Jackson and Moghaddam, 2001; Louilot and Beeson 2000), with BLA DA exerting an inhibitory influence on NAc DA under normal circumstances (Louilot et al, 1985). Repeated exposure to an escalating dose of AMPH has been shown to disrupt the balance of DA neurotransmission in the NAc core and shell, and to lead to an exaggerated conditioned freezing responses to a tone previously paired with shock (Pezze et al, 2002), a form of conditioning well established to depend on the integrity of the BLA (Phillips and LeDoux, 1992). It is possible that such imbalances in the NAc core and shell DA could also lead to attenuation of BLA control over appetitive behavior.

There is also evidence to suggest that the function of the BLA may be compromised following repeated AMPH exposure because of decreased DA tone in the $\mathrm{MPFC}$ (Paulson and Robinson, 1995; Pierce and Kalivas, 1997; Hedou et al, 2001). In the event of a decrease in DA levels in the $\mathrm{mPFC}$, there is a concomitant increase in responsiveness to glutamate, and an increased activity of mPFC pyramidal cells (Peterson et al, 2000; Hedou et al, 2001). Although this may have an excitatory influence on some subcortical structures such as the VTA and NAc, neurophysiological evidence suggests that it can have a suppressive effect on the BLA through recruitment of inhibitory interneurons (Rosenkranz and Grace, 2001). A dysfunctional BLA account here would be consistent with a considerable number of reports implicating decreased activation in the amygdala in schizophrenic patients (Schneider et al, 1998; Calder et al, 2001; Gur et al, 2002; Takahashi et al, 2004), and further validates the use of AMPH sensitization in modeling certain aspects of schizophrenia in animals.

\section{Effect of Repeated AMPH on Acquisition of Spatial Learning}

The present findings suggest that under conditions in which HPC-dependent and BLA-dependent information are in direct competition over the control of appetitive behavior, AMPH exposure causes HPC-mediated input to dominate behavior. It is noteworthy, however, that AMPH exposure did not facilitate the acquisition of conditional spatial learning in this study, which is consistent with previous studies showing the absence of facilitation on other measures of HPC-dependent spatial learning after AMPH exposure. Thus, Russig et al, (2003) failed to show any effects of a sensitizing regimen of repeated AMPH administration on the acquisition rate of water maze performance. There has even been a demonstration of impairment in nonassociative spatial learning in mice after repeated AMPH administration (Mandillo et al, 2003). Such failures to observe repeated AMPH-induced facilitation in spatial learning may indicate that the neural adaptations caused by repeated AMPH exposure serve to enhance HPC control over behavioral output at the level of expression, as opposed to enhancing HPC-dependent associative learning at the level of acquisition. This may explain why Gelowitz et al (1994) observed an enhanced acquisition of spatial learning in the Morris water maze in rats that have not only been pretreated with AMPH but have also been given acute doses of AMPH before each session of training throughout the course of acquisition.

\section{Neural Mechanism of Enhanced HPC Control over Appetitive Behavior}

There are a number of putative mechanisms by which HPC-dependent information may gain predominant control over behavior after AMPH exposure. The presence of a positive correlation between the degree of locomotor sensitization exhibited by each animal and the degree of conditioned place preference exhibited by the same animal in this study strongly points to the fact that the neural and neurochemical alterations that underlie locomotor sensitization also contribute to the facilitation of place learning. It is well established that sensitized animals have enhanced activity of the meso-accumbens DA system (Kalivas and Stewart, 1991; Henry and White, 1992), which is dependent on the extent of behavioral sensitization exhibited by the animal (Brady et al, 2003) and specifically related to behaviorally significant information (Wan and Peoples, 2008). This DA pathway has also been implicated in attributing incentive salience to reward-associated cues, thereby making cues powerful elicitors of Pavlovian approach responses (Robinson and Berridge, 1993, 2001). Thus, in line with this incentive salience hypothesis, AMPH exposure may have led to excessive attribution of salience to HPC inputs. This aberrant salience attribution could arise as a direct result of a state of HPC overdrive in AMPH withdrawal, in light of recent electrophysiological evidence showing that repeated AMPH administration augments ventral hippocampal output, which in turn increases baseline/tonic DA activity in the NAc (Lodge and Grace, 2008). 
Neural Mechanism of AMPH-Induced Alteration in the Balance of Limbic Control over Appetitive Behavior

The present findings suggest that repeated AMPH exposure disrupts the balance of competing limbic control over appetitive behavior. The aberrant regulation of HPC and BLA control over conditioned preference behavior is likely to be a consequence of altered interactions between converging dopaminergic inputs and limbic glutamatergic inputs at the level of the NAc and mPFC. It is well established that repeated psychostimulant exposure enhances meso-accumbens DA activity (Vanderschuren and Kalivas, 2000). Electrophysiological evidence lends support to the idea that NAc DA regulates the balance of limbic information processing by strengthening the most behaviorally relevant and salient inputs, while inhibiting other competing inputs. Most pertinent is the demonstration by Floresco et al (2001) that coactivation of the NMDA receptor-mediated glutamatergic HPC-NAc pathway and postsynaptic D1 receptors in the NAc has the net effect of enhancing HPC-evoked activity, and facilitating mesoaccumbens DA release. Importantly, this not only ensures that there is a preferential enhancement of HPC inputs but also serves to inhibit the effect of subsequent BLA input to the same neuron. Thus, as discussed previously, it is conceivable that repeated AMPH induces an abnormal state of hyperdopaminergic activity in the NAc as a consequence of HPC overactivity, leading to HPC dominance over behavioral output and a concomitant suppression of BLA control over behavior, as seen in this study.

Furthermore, substantial evidence indicates that repeated AMPH exposure leads to marked deficits in cognitive and executive functions that are accompanied by reduced function of the meso-cortical DA system. Thus, a sensitizing regimen of AMPH administration impairs the spatial working memory in primates, an effect accompanied by a reduced turnover of DA in the prefrontal cortex (Castner et al, 2005). Visual attentional performance is also impaired in $\mathrm{AMPH}$-sensitized rats, with evidence of a decreased function of D1 receptors in mPFC (Fletcher et al, 2007). An opposing input selection mechanism similar to that between HPC and BLA inputs seems to operate between HPC and mPFC inputs in the NAc. Thus, when HPC is activated, LTP is induced at HPC inputs in the NAc because of D1 receptor and NMDAR activation, and LTD is induced at mPFC inputs through $\mathrm{D} 2$ receptor activation, to shift processing in the NAc toward limbic information. Conversely, when mPFC activity is dominant, LTD is induced at HPC inputs, and LTP at mPFC inputs, because of decreased D2R stimulation (decreased tonic DA transmission in NAc; Goto and Grace 2005b), providing a neural mechanism for set shifting of behavioral strategies. Cocaine sensitization has been shown to disrupt the induction of synaptic plasticity in the NAc that correlated with an increase in perseverative errors when a switch in response strategy was required, indicative of reduced PFC influence upon NAc activity (Goto and Grace, 2005b).

In summary, this study provides the first functional demonstration of altered limbic information processing and consequent control over appetitive behavior after a sensitizing regimen of repeated AMPH administration in mice. The manifestation of an aberrant limbic control over conditioned preference behavior is likely to be driven by altered interactions between converging dopaminergic inputs and limbic glutamatergic inputs within the corticostriatal circuitry, coupled with an overactive HPC and an underactive BLA. These findings, together with previous demonstrations of competitive interactions between HPC and BLA-mediated learning (McDonald and White, 1993; Chai and White, 2004; Ito et al, 2006), indicate that the balance of HPC-NAc and BLA-NAc throughput is normally kept under tight regulation. Dysregulation in these systems, as seen here as a result of repeated AMPH treatment, can lead to manifestations of abnormal patterns of behavior, which may include psychotic symptoms in schizophrenia (Castner and Goldman-Rakic, 2003) and increased contextual control over drug-craving and relapse in drug addicts due to salience misattribution.

\section{ACKNOWLEDGEMENTS}

This work was supported by a Wellcome Trust Research Career Development Fellowship Grant WT078197 awarded to RI. We are grateful to Dr David Sanderson for conducting the surgeries in the HPC group, to Mr Greg Daubney for his assistance with histology, and to Prof. Nick Rawlins for helpful discussions.

\section{DISCLOSURE}

The authors declare no conflict of interest.

\section{REFERENCES}

Bjijou Y, De Deurwaerdere P, Spampinato U, Stinus L, Cador M (2002). D-amphetamine-induced behavioral sensitization: effect of lesioning dopaminergic terminals in the medial prefrontal cortex, the amygdala and the entorhinal cortex. Neuroscience 109: 499-516.

Brady AM, Glick SD, O’Donnell P (2003). Changes in electrophysiological properties of nucleus accumbens neurons depend on the extent of behavioral sensitization to chronic methamphetamine. Ann N Y Acad Sci 1003: 358-363.

Burns LH, Robbins TW, Everitt BJ (1993). Differential effects of excitotoxic lesions of the basolateral amygdala, ventral subiculum and medial prefrontal cortex on responding with conditioned reinforcement and locomotor activity potentiated by intra-accumbens infusions of D-amphetamine. Behav Brain Res 55: 167-183.

Calder AJ, Lawrence AD, Young AW (2001). Neuropsychology of fear and loathing. Nat Rev 2: 352-363.

Cardinal RN, Parkinson JA, Hall J, Everitt BJ (2002). Emotion and motivation: the role of the amygdala, ventral striatum, and prefrontal cortex. Neurosci Biobehav Rev 26: 321-352.

Castner SA, Goldman-Rakic PS (2003). Amphetamine sensitization of hallucinatory-like behaviors is dependent on prefrontal cortex in nonhuman primates. Biol psychiatry 54: 105-110.

Castner SA, Vosler PS, Goldman-Rakic PS (2005). Amphetamine sensitization impairs cognition and reduces dopamine turnover in primate prefrontal cortex. Biol psychiatry 57: 743-751.

Chai SC, White NM (2004). Effects of fimbria-fornix, hippocampus, and amygdala lesions on discrimination between proximal locations. Behav Neurosci 118: 770-784.

Cho YH, Friedman E, Silva AJ (1999). Ibotenate lesions of the hippocampus impair spatial learning but not contextual fear conditioning in mice. Behav Brain Res 98: 77-87. 
Deacon RM, Bannerman DM, Kirby BP, Croucher A, Rawlins JN (2002). Effects of cytotoxic hippocampal lesions in mice on a cognitive test battery. Behav Brain Res 133: 57-68.

Everitt BJ, Morris KA, O'Brien A, Robbins TW (1991). The basolateral amygdala-ventral striatal system and conditioned place preference: further evidence of limbic-striatal interactions underlying reward-related processes. Neuroscience 42: 1-18.

Ferbinteanu J, McDonald RJ (2001). Dorsal/ventral hippocampus, fornix and conditioned place preference. Hippocampus 11: 187-200.

Fletcher PJ, Tenn CC, Sinyard J, Rizos Z, Kapur S (2007). A sensitizing regimen of amphetamine impairs visual attention in the 5-choice serial reaction time test: reversal by a D1 receptor agonist injected into the medial prefrontal cortex. Neuropsychopharmacology 32: 1122-1132.

Floresco SB, Blaha CD, Yang CR, Phillips AG (2001). Modulation of hippomcampal and amygdalar-evoked activity of nucleus accumbens neurons by dopamine: cellular mechanisms of input selection. J Neurosci 21: 2851-2860.

French SJ, Totterdell S (2003). Individual nucleus accumbensprojection neurons receive both basolateral amygdala and ventral subicular afferents in rats. Neuroscience 119: 19-31.

Gelowitz DL, Richardson JS, Wishart TB, Yu PH, Lai CT (1994). Chronic L-deprenyl or L-amphetamine: equal cognitive enhancement, unequal MAO inhibition. Pharmacol, Biochem Behav 47: 41-45.

Goto Y, Grace AA (2005). Dopamine-dependent interactions between limbic and prefrontal cortical plasticity in the nucleus accumbens: disruption by cocaine sensitization. Neuron 47: 255-266.

Gur RE, McGrath C, Chan RM, Schroeder L, Turner T, Turetsky BI et al (2002). An fMRI study of facial emotion processing in patients with schizophrenia. Am $J$ Psychiatry 159: 1992-1999.

Harmer CJ, Hitchcott PK, Morutto SL, Phillips GD (1997). Repeated amphetamine enhances stimulated mesoamygdaloid dopamine transmission. Psychopharmacology 132: 247-254.

Harmer CJ, Phillips GD (1998). Enhanced appetitive conditioning following repeated pretreatment with d-amphetamine. Behav Pharmacol 9: 299-308.

Hedou G, Homberg J, Feldon J, Heidbreder CA (2001). Expression of sensitization to amphetamine and dynamics of dopamine neurotransmission in different laminae of the rat medial prefrontal cortex. Neuropharmacology 40: 366-382.

Henry DJ, White FJ (1992). Electrophysiological correlates of psychomotor stimulant-induced sensitization. Ann N Y Acad Sci 654: $88-100$.

Hitchcott PK, Harmer CJ, Phillips GD (1997). Enhanced acquisition of discriminative approach following intra-amygdala d-amphetamine. Psychopharmacology 132: 237-246.

Ito R, Robbins TW, McNaughton BL, Everitt BJ (2006). Selective excitotoxic lesions of the hippocampus and basolateral amygdala have dissociable effects on appetitive cue and place conditioning based on path integration in a novel Y-maze procedure. Eur J Neurosci 23: 3071-3080.

Jackson ME, Moghaddam B (2001). Amygdala regulation of nucleus accumbens dopamine output is goverened by the prefrontal cortex. J Neurosci 21: 676-681.

Kalivas PW, Stewart J (1991). Dopamine transmission in the initiation and expression of drug- and stress-induced sensitization of motor activity. Brain Res Brain Res Rev 16: 223-244.

Lodge DJ, Grace AA (2008). Amphetamine activation of hippocampal drive of mesolimbic dopamine neurons: a mechanism of behavioral sensitization. J Neurosci 28: 7876-7882.

Louilot A, Beeson C (2000). Specificity of amygdalostriatal interactions in the involvement of mesencephalic dopaminergic neurons in affective perception. Neuroscience 96: 73-82.
Louilot A, Simon H, Taghzouti K, Le Moal M (1985). Modulation of dopaminergic activity in the nucleus accumbens following facilitation or blockade of the dopaminergic transmission in the amygdala: a study by in vivo differential pulse volatemmetry. Brain Res 346: 141-145.

Mandillo S, Rinaldi A, Oliverio A, Mele A (2003). Repeated administration of phencyclidine, amphetamine and MK-801 selectively impairs spatial learning in mice: a possible model of psychotomimetic drug-induced cognitive deficits. Behav Pharmacol 14: 533-544.

McDonald RJ, White NM (1993). A triple dissociation of memory systems: hippocampus, amygdala, and dorsal striatum. Behav Neurosci 107: 3-22.

Morris RG, Garrud P, Rawlins JN, O'Keefe J (1982). Place navigation impaired in rats with hippocampal lesions. Nature 297: 681-683.

Mulder AB, Hodenpijl MG, Lopes da Silva FH (1998). Electrophysiology of the hippocampal and amygdaloid projections to the nucleus accumbens of the rat: convergence, segregation, and interaction of inputs. J Neurosci 18: 5095-5102.

Nelson A, Killcross S (2006). Amphetamine exposure enhances habit formation. J Neurosci 26: 3805-3812.

Nordquist RE, Voorn P, de Mooij-van Malsen JG, Joosten RN, Pennartz CM, Vanderschuren LJ (2007). Augmented reinforcer value and accelerated habit formation after repeated amphetamine treatment. Eur Neuropsychopharmacol 17: 532-540.

O'Keefe J, Nadel L (1978). The Hippocampus as a Cognitive Map. OUP: Oxford.

Packard MG, Knowlton BJ (2002). Learning and memory functions of the basal ganglia. Annu Rev Neurosci 25: 563-593.

Paulson PE, Robinson TE (1995). Amphetamine-induced timedependent sensitization of dopamine neurotransmission in the dorsal and ventral striatum: a microdialysis study in behaving rats. Synapse (New York), NY 19: 56-65.

Paxinos G, Franklin K (2001). The mouse brain in stereotaxic coordinates. In: Second edn. New York: Academic Press.

Pennartz CM, Groenewegen HJ, Lopes da Silva FH (1994). The nucleus accumbens as a complex of functionally distinct neuronal ensembles: an integration of behavioural, electrophysiological and anatomical data. Prog Neurobiol 42: 719-761.

Peterson JD, Wolf ME, White FJ (2000). Altered responsiveness of medial prefrontal cortex neurons to glutamate and dopamine after withdrawal from repeated amphetamine treatment. Synapse (New York), NY 36: 342-344.

Pezze MA, Fedon J, Mursphy CA (2002). Increased conditioned fear response and altered balanace of dopamine in the shell and core of the nucleus accumbens during amphetamine withdrawal. Neuropharmacology 42: 633-643.

Phillips RG, LeDoux JE (1992). Differential contribution of amygdala and hippocampus to cued and contextual fear conditioning. Behav Neurosci 106: 274-285.

Pierce RC, Kalivas PW (1995). Amphetamine produces sensitized increases in locomotion and extracellular dopamine preferentially in the nucleus accumbens shell of rats administered repeated cocaine. J Pharmacol Exp Ther 275: 1019-1029.

Pierce RC, Kalivas PW (1997). A circuitry model of the expression of behavioral sensitization to amphetamine-like psychostimulants. Brain Res Brain Res Rev 25: 192-216.

Robinson TE, Becker JB (1986). Enduring changes in brain and behavior produced by chronic amphetamine administration: a review and evaluation of animal models of amphetamine psychosis. Brain Res 396: 157-198.

Robinson TE, Berridge KC (1993). The neural basis of drug craving: an incentive-sensitization theory of addiction. Brain Res Brain Res Rev 18: 247-291.

Robinson TE, Berridge KC (2001). Incentive-sensitization and addiction. Addiction (Abingdon, England) 96: 103-114. 
Rosenkranz JA, Grace AA (2001). Dopamine attenuates prefrontal cortical suppression of sensory inputs to the basolateral amygdala of rats. J Neurosci 21: 4090-4103.

Russig H, Durrer A, Yee BK, Murphy CA, Feldon J (2003). The acquisition, retention and reversal of spatial learning in the morris water maze task following withdrawal from an escalating dosage schedule of amphetamine in wistar rats. Neuroscience 119: $167-179$.

Schmitt WB, Arianpour R, Deacon RMJ, Seeburg PH, Sprengel R, Rawlins JNP et al (2004). The role of hippocampal glutamate receptor-A-dependent synaptic plasticity in conditional learning: the importance of spatiotemporal discontiguity. J Neurosci 18: 7277-7282.

Schneider F, Weiss U, Kessler C, Salloum JB, Posse S, Grodd W et al (1998). Differential amygdala activation in schizophrenia during sadness. Schizophrenia Res 34: 133-142.

Stalkaner TA, Roesch MR, Franz TM, Calu DJ, Singh T, Schoenbaum GS (2007). Cocaine-induced decision- making deficits are mediated by miscoding in basolateral amygdala. Nature Neurosci 10: 949-951.

Takahashi H, Koeda M, Oda K, Matsuda T, Matsushima E, Matsuura $M$ et al (2004). An fMRI study of differential neural response to affective pictures in schizophrenia. NeuroImage 22: 1247-1254.

Taylor JR, Robbins TW (1984). Enhanced behavioural control by conditioned reinforcers following microinjections of d-amphe- tamine into the nucleus accumbens. Psychopharmacology 84: 405-412.

Taylor JR, Horger BA (1999). Enhanced responding for conditioned reward produced by intra-accumbens amphetamine is potentiated after cocaine sensitization. Psychopharmacology 142: $31-40$.

Taylor JR, Jentsch JD (2001). Repeated intermittent administration of psychomotor stimulant drugs alters the acquisition of Pavlovian approach behavior in rats: differential effects of cocaine, d-amphetamine and 3,4- methylenedioxymethamphetamine ('Ecstasy'). Biological Psychiatry 50: 137-143.

Vanderschuren LJ, Kalivas PW (2000). Alterations in dopaminergic and glutamatergic transmission in the induction and expression of behavioral sensitization: a critical review of preclinical studies. Psychopharmacology 151: 99-120.

Wan X, Peoples LL (2008). Amphetamine exposure enhances accumbal responses to reward-predictive stimuli in a pavlovian conditioned approach task. J Neurosci 28: 7501-7512.

White NM, McDonald RJ (1993). Acquisition of a spatial conditioned place preference is impaired by amygdala lesions and improved by fornix lesions. Behav Brain Res 55: 269-281.

Wyvell CL, Berridge KC (2000). Intra-accumbens amphetamine increases the conditioned incentive salience of sucrose reward: enhancement of reward 'wanting' without enhanced 'liking' or response reinforcement. J Neurosci 20: 8122-8130. 